\title{
Assessing the values of circulating immune complexes in multiple sclerosis patients following immunomodulator or corticosteroid treatment
}

\author{
ANY DOCU AXELERAD ${ }^{1}$, ALINA ZORINA STROE ${ }^{1}$, ANCA ELENA GOGU $^{2}$ and DANIEL DOCU AXELERAD ${ }^{3}$ \\ ${ }^{1}$ Department of Neurology, Faculty of General Medicine, 'Ovidius' University of Constanta, 900470 Constanta; \\ ${ }^{2}$ Department of Neurology, Faculty of General Medicine, Victor Babeș University of Medicine and Pharmacy Timișoara, \\ 300041 Timisoara; ${ }^{3}$ Department of Sports, Faculty of Physical Education and Sports, \\ 'Ovidius' University of Constanta, 900470 Constanta, Romania
}

Received January 5, 2021; Accepted February 4, 2021

DOI: $10.3892 /$ etm.2021.9974

\begin{abstract}
Multiple sclerosis is defined as an immune-mediated disease that affects the central nervous system, and also is characterized by the presence of immune cells and mediators which contribute to the subsidiary neuroinflammation associated with multiple sclerosis. Throughout the evolution of multiple sclerosis, it has been observed that circulating immune complexes (CICs) have higher values in these patients, especially in the acute phase of the disease. Thus, the aim of the present study was to observe, if in acute attack, relapsing-remitting multiple sclerosis patients still present high values of CICs after treatment with glatiramer and prednisone. We divided 70 patients with multiple sclerosis with high values of CICs into two treatment groups, one treated with glatiramer (Copaxone) (immunomodulatory treatment) and the other with prednisone (corticosteroid treatment). After three months of treatment, we assessed the levels of CICs of the two multiple sclerosis groups and we observed that the patients that followed the immunomodulatory treatment had lower values of CICs than the group that followed the corticosteroid treatment. In addition, another observation established was that the glatiramer treatment group had higher levels of vitamin D in the serum than the prednisone group of multiple sclerosis patients. To conclude, better outcomes, from the point of view of the results obtained from the comparative analysis of the values of CICs and vitamin D, were demonstrated by following immunomodulatory treatment.
\end{abstract}

Correspondence to: Dr Alina Zorina Stroe, Department of Neurology, Faculty of General Medicine, 'Ovidius' University of Constanta, 1 Aleea Universității, 900470 Constanta, Romania E-mail: zorina.stroe@yahoo.com

Key words: multiple sclerosis, circulating immune complexes, corticosteroid treatment, immunomodulator treatment, vitamin D

\section{Introduction}

Multiple sclerosis presents as a chronic central nervous system inflammatory disease which determines processes of demyelination and neurodegeneration. Multiple sclerosis is characterized by impairments in motor and sensory function caused by immune-mediated inflammation, demyelination and subsidiary axonal damage (1). The evolution of the disease is defined by episodes of neurological impairments and deficits that can be succeeded by a stage of remission or progression. The prevalence consists of 2.5 million people worldwide who are afflicted with multiple sclerosis, and these reports also have areal variability (1).

Multiple sclerosis is defined by the invasion of T lymphocytes, B lymphocytes, macrophages, and natural killer cells and is accompanied by demyelination and axonal damage (1).

Relapsing-remitting multiple sclerosis is defined as the most prevalent form of the disease and is characterized by relapses or acute attacks (aggravation of neurological symptoms during $24 \mathrm{~h}$ or longer, without the presence of fever). In evolution, the attack can proceed to remission automatically or consequent to the treatment with corticosteroids or pulse therapy (2). The majority of patients are initially diagnosed with relapsingremitting multiple sclerosis. The most generally detected symptoms include optic neuritis, motor or sensory deficits of the limbs, motor impairments of coordination, loss of balance, myelitis, sphincter dysfunction and cognitive-behavioral impairment, either separately or in association $(3,4)$. Subsequent to relapsing-remitting multiple sclerosis, the majority of patients traverse into a secondary progressive course with continuous intensification of impairment (3).

The principles of treatment are based on the usage of disease modifying therapies or immunomodulators that target impediment of the progression of relapsing-remitting multiple sclerosis and prevent relapse by diminishing circulating immune cells (CICs) or by limiting these cells from passing the blood-brain barrier, by decreasing the inflammatory response $(5,6)$.

The immunological development in the pathophysiology of multiple sclerosis has been determined through the results 
of experimental studies established using murine configurations and specimens from multiple sclerosis patients (7-9). Primarily, in the peripheral lymph nodes, the stimulation of autoreactive $\mathrm{T}$ cells and $\mathrm{B}$ cells occurs through activation and differentiation toward effector cells. The crucial part in the pathogenesis of multiple sclerosis is executed by effector $\mathrm{CD}^{+}$ $\mathrm{T}$ cells, $\mathrm{T}$ helper 1 and $\mathrm{T}$ helper 17 cells. The numbers of the mentioned subpopulations are higher in the peripheral blood and central nervous system, especially in the cerebrospinal fluid and the perivascular space (7-9).

Activated $\mathrm{T}$ and $\mathrm{B}$ cells proceed to the blood-brain barrier, the interruption of which indicates the incipient phase of the disease, and these cells enter the central nervous system, where they are additionally stimulated by local antigen-presenting cells $(10,11)$. In the central nervous system, macrophages and activated $\mathrm{CD}^{+}$and $\mathrm{CD}^{+} \mathrm{T}$ cells target the myelin constituents and generate cytokines and chemokines that engage additional autoreactive cells having as source the peripheral blood $(4,12,13)$. The mentioned cells also activate B cells, that develop into antibody-generating plasma cells; cause, preserve and restimulate $\mathrm{CD}^{+} \mathrm{T}$ cells; and generate proinflammatory cytokines $(13,14)$. In general, the mechanisms stated before increment inflammation produce demyelination and axonal destruction $(15,16)$. In the determinative stages of the disease, the inflammatory response is reinstated with microglial activation and chronic neurodegeneration $(17,18)$.

In the medical literature, the presence of CICs has been reported in the serum of multiple sclerosis patients since 1976 (19).

\section{Patients and methods}

Patients. Circulating immune complexes (CICs) were analyzed from blood samples of 70 multiple sclerosis patients with relapsing-remitting form. The patients were recruited during the period of January 1, 2017 to August 1, 2020 at Constanta County Hospital in Romania. A total of 70 multiple sclerosis patients participated in this study. A total of 44 subjects $(62.86 \%)$ were women and $26(37.14 \%)$ were men. The mean age of the patients was 28.3 years, and the age range was 26-40 years. The current study was approved by the Ethics Committee of the Constanta Clinical Hospital, Romania. Written informed consent was obtained from all subjects.

Inclusion criteria were patients diagnosed with multiple sclerosis relapsing-remitting form, diagnosed by a neurologist. Exclusion criteria were i) the presence of other immunological diseases, such as rheumatic diseases (systemic lupus erythematosus, mixed connective tissue disease, rheumatoid arthritis, Sjoegren's syndrome, nodular periarteritis, Felty's syndrome, Reiter's syndrome, Bechterew's disease); ii) the presence of neoplastic diseases infectious type including viral infections (hepatitis B, cytomegalovirus infection, Ebstein Barr, subacute sclerosing panencephalitis) and bacterial infections (infectious endocarditis, disseminated gonorrhea, syphilis, streptococcal and meningococcal infection); and parasitosis (malaria, schistosomiasis, trypanosomiasis, toxoplasmosis); and iii) the presence of other chronic pathologies including glomerulonephritis, ulcerative colitis, Crohn's disease, idiopathic interstitial pneumonia, cystic fibrosis, multiple sclerosis and thrombotic purpura thrombocytopenic hepatitis.
Patient groups and treatment. In the present study, we aimed to assess the values of CICs in the relapsing-remitting multiple sclerosis patients in acute attack and we divided 70 patients with multiple sclerosis with high values of CICs into two treatment groups: One treated with glatiramer (Copaxone) (immunomodulatory treatment) and the other with prednisone (corticosteroid treatment). After three months of treatment, we assessed the levels of CICs in the two multiple sclerosis treatment groups. In addition, we assessed the levels of vitamin D in both of the groups to observe if any difference was visible between the levels of vitamin D in both groups. Vitamin D is related to the bone health and calcium metabolism, along with the general immunity level of the organism, currently being of general interest in multiple sclerosis.

The therapeutic strategy for each patient was decided upon by the treating doctor on the basis of the best possible solution for each patient. Glatiramer acetate represents a synthetic protein which simulates myelin basic protein, a component of the myelin that isolates nerve fibers located in the brain and spinal cord. This drug functions by blocking myelin-damaging T-cells using a mechanism which is not entirely understood. Prednisone represents one of a group of corticosteroids that contribute to relieve inflammation in different parts of the body. Corticosteroids are used in multiple sclerosis for their ability to seal the damaged blood-brain barrier and decrease inflammation located in the central nervous system. Patients from the prednisone treatment group received 1 milligram Prednisone per kilogram of body weight per day, during the three months. The patients from the Copaxone treatment group received three injections of Copaxone $(40 \mathrm{mg} / \mathrm{ml}$ solution for injection in pre-filled syringe) per week during the three months.

CIC serum test method. The venous blood collected was treated according to the protocols of the hospital's analysis laboratory, using the ELISA technique, with the following methodology. CICs in the patient's serum were fixed by the Fc fragment on $\mathrm{Clq}$ from the microplate; in order to quantify the presence of CIC-IgG complexes, peroxidase-conjugated anti-IgG antibodies and then tetramethylbenzidine substrate were afterwards added. The color intensity obtained was directly proportional to the level of C1q-CIC complexes related to the solid phase. The venous blood collected was treated according to the protocols of the hospital's analysis laboratory, using the immunochemical method with detection by electrochemiluminescence. In addition, total vitamin D was measured (vitamin D3, vitamin D2 and other hydroxylated metabolites of vitamin D).

Statistical analysis. All statistical analyses were performed using IBM SPSS Statistics 20 (IBM Corp.). Data from the patients were compared using the non-parametric Mann-Whitney's U test. P-values $<0.05$ were considered to indicate statistical significance.

\section{Results}

A Mann-Whitney $U$ test was run to determine whether there were differences in the results of the initial CIC serum test performed on the multiple sclerosis patients treated 
Table I. Results of the CIC serum test in the multiple sclerosis patients $(\mathrm{N}=70)$.

\begin{tabular}{lccr}
\hline Group_Treatment & Number & $\begin{array}{c}\text { Mean } \\
\text { rank }\end{array}$ & $\begin{array}{c}\text { Sum of } \\
\text { ranks }\end{array}$ \\
\hline CIC_Initial & & & \\
Glatiramer acetate & 35 & 36.83 & 1,289 \\
Prednisone & 35 & 34.17 & 1,196 \\
Total & 70 & & \\
CIC_Final & & & \\
Glatiramer acetate & 35 & 18 & 630 \\
Prednisone & 35 & 53 & 1,855 \\
Total & 70 & & \\
\hline
\end{tabular}

with glatiramer acetate vs. the patients treated with prednisone. Distributions of the results for both of the groups of patients were similar, as assessed at a first glance. CIC dosing results were not statistically significant between the glatiramer acetate treatment group (mean rank=36.83) and the prednisone treatment group of multiple sclerosis patients (mean rank=34.17) $(\mathrm{U}=566, \mathrm{z}=-0.516, \mathrm{P}=0.575)$. The results are provided in Tables I and II.

A Mann-Whitney U test was run to determine whether there were differences in the results of the final CIC serum test ( 3 months following the initial test) performed on the multiple sclerosis patients treated with glatiramer acetate and on the multiple sclerosis patients treated with prednisone. Distributions of the results for both of the groups of patients were not similar, as assessed at a first glance. The results from the CIC serum test in the glatiramer acetate treatment group (mean rank=18) were statistically significantly lower when compared to the results from CIC serum test in the prednisone treatment group of multiple sclerosis patients (mean rank=53) $(\mathrm{U}=0.000, \mathrm{P}<0.001)$. The results are provided in Tables I and II.

A Mann-Whitney $U$ test was run to determine whether there were differences in the results of the vitamin D serum test performed on the multiple sclerosis patients treated with glatiramer acetate and on the multiple sclerosis patients treated with prednisone. Distributions of the results for both of the groups of patients were not similar, as assessed by at a first glance. The results from the vitamin D serum test in the glatiramer acetate treatment group (mean rank=53) were statistically significantly higher when compared with the results from the vitamin D serum test in the prednisone treatment group of multiple sclerosis patients (mean rank=18) $(\mathrm{U}=0.000$, $\mathrm{P}<0.001)$. The results are provided in Tables III and IV.

In our study performed on 70 patients with multiple sclerosis relapsing-remitting form in the period of active disease, with 35 patients treated with glatiramer acetate immunomodulator (Copaxone) and 35 patients treated with prednisone only in the active phase of the disease, we observed that the CICs were relatively the same at the active phase of the disease, before initiation of the medication.

Following three months of treatment, we observed that the immunomodulator treated group of multiple sclerosis patients obtained statistically lower values for the CIC test than the
Table II. Statistical analysis of the results obtained by the multiple sclerosis patients $(\mathrm{N}=70)$ for the CIC serum test. ${ }^{a}$

\begin{tabular}{lcc}
\hline Statistical variables & CIC_Initial & CIC_Final \\
\hline Mann-Whitney U & 566 & 0.000 \\
Wilcoxon W & 1,196 & 630 \\
z-value & -0.561 & -7.241 \\
Asymp. Sig. (2-tailed) & 0.575 & 0.000 \\
\hline
\end{tabular}

${ }^{a}$ Grouping variable: Group_Treatment. CIC, circulating immune complex.

Table III. Median results of the assessment of vitamin D between the two treatment groups of multiple sclerosis patients $(\mathrm{N}=70)$.

\begin{tabular}{lccr}
\hline & \multicolumn{3}{c}{ Vitamin D } \\
\cline { 2 - 4 } Group_treatment & Number & $\begin{array}{c}\text { Mean } \\
\text { rank }\end{array}$ & $\begin{array}{c}\text { Sum of } \\
\text { ranks }\end{array}$ \\
\hline Glatiramer acetate & 35 & 53 & 1,855 \\
Prednisone & 35 & 18 & 630 \\
Total & 70 & & \\
\hline
\end{tabular}

Table IV. Statistical results of the assessment of vitamin D between the two treatment groups of multiple sclerosis patients $(\mathrm{N}=70){ }^{\mathrm{a}}$

\begin{tabular}{lr}
\hline Statistical variables & Vitamin D \\
\hline Mann-Whitney U & 0.000 \\
Wilcoxon W & 630 \\
Z-value & -7.211 \\
Asymp. Sig. two-tailed) & 0.000
\end{tabular}

${ }^{\mathrm{a}}$ Grouping variable: Group_Treatment.

group of patients that was treated with prednisone only in the acute phase.

Another observation of our study was that the levels of vitamin D were statistically higher in the group of patients treated with immunomodulators than in the group of patients treated with corticosteroids.

\section{Discussion}

In the present study, we were interested in ascertaining whether our 70 patients with multiple sclerosis obtained high values of circulating immune complexes (CICs) in the active phase and if the high values of CICs were influenced by the category of the treatment chosen.

Immune complex formation is a hallmark of both infectious and autoimmune disorders. Tanaka et al examined the serum 
of 21 multiple sclerosis patients for CICs and anti-endothelial cell antibodies and revealed higher titres of CICs in the serum of patients with multiple sclerosis, especially the patients with active disease (20).

In a previous study, CICs were more frequently detected in patients with active disease than in patients that were recovering from an exacerbation and patients whose disease showed no progression in the last years (21).

The influence of immune complexes has been demonstrated related to the impairments that CICs experience in the blood-brain barrier and this factor is especially important in multiple sclerosis (22).

In the evolution of multiple sclerosis, pathological disruption of the blood-brain barrier was identified (23) through studies in vivo using contrast induced CT scan of the lesions in multiple sclerosis (24-27).

Dasgupta et al reported the prevalence of CICs in the serum of 254 multiple sclerosis patients, showing a 35\% positivity of CICs in multiple sclerosis. The incidence of CICs in acute relapse, progressive, remission, and stable state of multiple sclerosis was 33.3, 30.2, 26.1 and 23.1, respectively, compared with 7.75 and $8.82 \%$ among normal and neurologic controls (21).

In another study, Dasgupta et al studied the prevalence of myelin basic protein which is an antigenic component of CICs in patients with multiple sclerosis, demonstrating that myelin basic protein was found to be an antigenic component in some CICs isolated from the sera of some multiple sclerosis patients. From the 22 samples of multiple sclerosis patients, 15 were CIC-positive and 6 of 7 samples from patients in relapse and of the 15 CIC-positive serum, 9 samples were also positive for myelin basic protein (28).

Myelin basic protein was discovered and dosed in the cerebrospinal fluid of patients with active demyelination, including multiple sclerosis $(29,30)$. In addition, myelin basic protein antibodies have been discovered in the cerebrospinal fluid of patients with multiple sclerosis (31).

In a study by Tachovsky et al, CICs were determined in $49 \%$ of serum from patients with multiple sclerosis, but the association between the presence of CICs and the severity of the disease was not established (32).

In a study by Patzold et al, CICs were detected in the sera of $46(33.3 \%)$ of 138 multiple sclerosis patients investigated. In cerebrospinal fluid, immune complexes were found in 24 (19.4\%) of the 124 samples of multiple sclerosis patients that were tested (33).

In a study by Jans et al, immune complexes were found in serum from 17 of the 32 multiple sclerosis patients with progressive form and in CSF from 9 of 31 multiple sclerosis patients in progressive form (34).

In a study by Wajgt $e t a l$, the levels of CICs in multiple sclerosis patients were higher than that in the control group and following prednisone therapy, a significant decrease in CIC level was found in the CSF of the multiple sclerosis patients (35).

The insufficiency of vitamin D represents a risk factor in the development of multiple sclerosis and is linked to increased disease activity in patients already diagnosed with multiple sclerosis $(36,37)$.

Research has revealed that patients with multiple sclerosis present a lower rise in serum 25-hydroxyvitamin D levels when compared with healthy controls, following treatment with the same amount of oral cholecalciferol supplementation (38).

These results provide evidence for the importance of the treatment elected for multiple sclerosis patients that can beneficially affect the level of CICs; the most effective treatment being an immunomodulator.

Moreover, this study observed higher levels of vitamin D among the multiple sclerosis patients that followed the immunomodulator treatment, compared to the multiple sclerosis patients that followed corticoid medication. Further studies on this issuer are required to formulate a justified theory.

\section{Acknowledgements}

Not applicable.

\section{Funding}

No funding was received.

\section{Availability of data and materials}

The datasets used and/or analyzed during the current study are available from the corresponding author on reasonable request.

\section{Authors' contributions}

ADA, AEG and AZS conceived and designed the study. AZS performed the literature research. ADA, AEG, AZS and DDA were involved in the interpretation of the results. ADA, AEG, AZS and DDA were involved in the writing of the manuscript. All authors have read and approved the final manuscript.

\section{Ethics approval and consent to participate}

The current study was approved by the Ethics Committee of the Constanta Clinical Hospital, Romania (no. 26/15.09.2020) and all the patients gave informed consent and signed a statement to that effect.

\section{Patient consent for publication}

Not applicable.

\section{Competing interests}

The authors declare that they have no competing interests.

\section{References}

1. Dendrou CA, Fugger L and Friese MA: Immunopathology of multiple sclerosis. Nat Rev Immunol 15: 545-558, 2015.

2. Howard J, Trevick S and Younger DS: Epidemiology of multiple sclerosis. Neurol Clin 34: 919-939, 2016.

3. Lublin FD, Reingold SC, Cohen JA, Cutter GR, Sørensen PS, Thompson AJ, Wolinsky JS, Balcer LJ, Banwell B, Barkhof F, et al: Defining the clinical course of multiple sclerosis: The 2013 revisions. Neurology 83: 278-286, 2014.

4. Compston A and Coles A: Multiple sclerosis. Lancet 372: 1502-1517, 2008. 
5. Tabansky I, Messina MD, Bangeranye C, Goldstein J, Blitz-Shabbir KM, Machado S, Jeganathan V, Wright P, Najjar S, Cao Y, et al: Advancing drug delivery systems for the treatment of multiple sclerosis. Immunol Res 63: 58-69, 2015.

6. Giovannoni G, Butzkueven H, Dhib-Jalbut S, Hobart J, Kobelt G Pepper G, Sormani MP, Thalheim C, Traboulsee A and Vollmer T: Brain health: Time matters in multiple sclerosis. Mult Scler Relat Disord 9 (Suppl 1): S5-S48, 2016.

7. Durelli L, Conti L, Clerico M, Boselli D, Contessa G, Ripellino P, Ferrero B, Eid P and Novelli F: T-helper 17 cells expand in multiple sclerosis and are inhibited by interferon. Ann Neurol 65: 499-509, 2009.

8. Langrish CL, Chen Y, Blumenschein WM, Mattson J, Basham B, Sedgwick JD, McClanahan T, Kastelein RA and Cua DJ: IL-23 drives a pathogenic $\mathrm{T}$ cell population that induces autoimmune inflammation. J Exp Med 201: 233-240, 2005.

9. Kebir H, Kreymborg K, Ifergan I, Dodelet-Devillers A, Cayrol R, Bernard M, Giuliani F, Arbour N, Becher B and Prat A: Human TH17 lymphocytes promote blood-brain barrier disruption and central nervous system inflammation. Nat Med 13: 1173-1175, 2007.

10. Tzartos JS, Friese MA, Craner MJ, Palace J, Newcombe J, Esiri MM and Fugger L: Interleukin-17 production in central nervous system-infiltrating $\mathrm{T}$ cells and glial cells is associated with active disease in multiple sclerosis. Am J Pathol 172: 146-155, 2008.

11. Rolla S, Bardina V, De Mercanti S, Quaglino P, De Palma R, Gned D, Brusa D, Durelli L, Novelli F and Clerico M: Th22 cells are expanded in multiple sclerosis and are resistant to IFN- $\beta$. J Leukoc Biol 96: 1155-1164, 2014.

12. Tachovsky TG, Lisak RP, Koprowski H, Theofilopoulos AN and Dixon FJ: Circulating immune complexes in multiple sclerosis and other neurological diseases. Lancet 2: 997-999, 1976.

13. Jacques C, Davous P and Baumann N: Circulating immune complexes and multiple sclerosis. Lancet 2: 408, 1977.

14. Goust JM, Chenais F, Carnes JE, Hames CG, Fudenbergh HH and Hogan HL: Abnormal T cell subpopulations and circulating immune complexes in the Guillain-Barré syndrome and multiple sclerosis. Neurology 28: 421-425, 1978

15. Deicher H, Schwabedissen HM, Liman W, Baruth B, Patzold U and Haller P: Immune complexes in cerebrospinal fluid and serum of patients with multiple sclerosis. In: Progress in Multiple Sclerosis Research. Bauer HG, Poser S and Ritter G (eds). Verlag, Berlin, Springer, pp200-206, 1980.

16. Jans H, Jersild C, Taaning E, Dybkjaer E, Fog T and Heltberg A: The occurrence of immune complexes in patients with multiple sclerosis. In: Progress in Multiple Sclerosis Research. Bauer HG, Poser S and Ritter G (eds). Verlag, Berlin, Springer, pp195-199, 1980.

17. Schocket AL, Carr RI and Hardtke MA: A comparison of I1 $25 \mathrm{Clq}$ binding, Raji cell binding, and lymphocytotoxic activity in multiple sclerosis. Clin Immunol Immunopathol 17: 477-481, 1980.

18. Trouillas P, Vincent $\mathrm{C}$ and Revillard JV: Clq binding circulating immune complexes in multiple sclerosis patients and their first-degree relatives: A distinctive immunological feature between sporadic and familial cases. J Clin Lab Immunol 4 $77-81,1980$.

19. Noronha AB, Antel JP, Roos RP and Medof EM: Circulating immune complexes in neurologic disease. Neurology 31: 1402-1407, 1981.

20. Tanaka Y, Tsukada N,Koh CS and Yanagisawa N: Anti-endothelial cell antibodies and circulating immune complexes in the sera of patients with multiple sclerosis. J Neuroimmunol 17: 49-59, 1987.
21. Dasgupta MK, Warren KG, Johny KV and Dossetor JB: Circulating immune complexes in multiple sclerosis: Relation with disease activity. Neurology 32: 1000-1004, 1982.

22. Tsukada N, Koh CS, Yanagisawa $\mathrm{N}$ and Tsukagoshi $\mathrm{H}$ : Nervous tissue injury induced by immune complexes. Acta Neuropathol 56: 279-284, 1982.

23. Broman T: Blood-brain barrier damage in multiple sclerosis Supravital test-observation. Acta Neurol Scand Suppl 40 (Suppl 10): S21-S24, 1964.

24. Aita JF, Benette DR, Anderson RE and Ziter F: Cranial CT appearance of acute multiple sclerosis. Neurology 28: 251-255, 1978.

25. Lane B, Carrol BA and Pedley TA: Computerized cranial tomography in cerebral diseases of white matter. Neurology 28 : 534-544, 1978 .

26. Ebers GC, Vinuela FV, Feasby T and Bass B: Multifocal CT enhancement in MS. Neurology 34: 341-346, 1984.

27. Hershey LA, Gado MH and Trotter JL: Computerized tomography in the diagnostic evaluation of multiple sclerosis. Ann Neurol 5: 32-39, 1979

28. Dasgupta MK, Catz I, Warren KG, McPherson TA, Dossetor JB and Carnegie PR: Myelin basic protein: A component of circulating immune complexes in multiple sclerosis. Can J Neurol Sci 10: 239-243, 1983.

29. Carson JH, Barbarese E, Braun PE and McPherson TA: Components in multiple sclerosis cerebrospinal fluid that are detected by radioimmunoassay for myelin basic protein. Proc Natl Acad Sci USA 75: 1976-1978, 1978.

30. McPherson TA, Gilpin A and. Seland TP: Radioimmunoassay of CSF for encephalitogenic basic protein: A diagnostic test for MS? Can Med Assn J 107: 856-859, 1972.

31. Panitch HS, Hafler DA and Johnson KP: Antibodiestomyelin basic protein in cerebrospinal fluid of patients with multiple sclerosis. In: Progress in Multiple Sclerosis Research. Bauer HJ, Poser SR and Ritter G (eds). Springer-Verlag, Heidelberg, New York, pp98-105, 1980.

32. Tachovsky TG, Koprowski H, Lisak RP, Theofilopoulos AN and Dixon FJ: Circulating immune complexes in multiple sclerosis and other neurological diseases. Lancet 308: 997-999, 1976.

33. Patzold U, Haller P, Baruth B, Liman W and Deicher H: Immune complexes in multiple sclerosis: Relation to clinical pattern. J Neurol 222: 249-260, 1980.

34. Jans H, Heltberg A, Zeeberg I, Kristensen JH, Fog T and Raun NE: Immune complexes and the complement factors $\mathrm{C} 4$ and $\mathrm{C} 3$ in cerebrospinal fluid and serum from patients with chronic progressive multiple sclerosis. Acta Neurol Scand 69: 34-38, 1984 .

35. Wajgt A, Górny MK and Jenek R: The influence of high-dose prednisone medication on autoantibody specific activity and on circulating immune complex level in cerebrospinal fluid of multiple sclerosis patients. Acta Neurol Scand 68: 378-385, 1983.

36. Munger KL, Levin LI, Hollis BW, Howard NS and Ascherio A: Serum 25-hydroxyvitamin D levels and risk of multiple sclerosis. JAMA 296: 2832-2838, 2006

37. Mowry EM, Krupp LB, Milazzo M, Chabas D, Strober JB, Belman AL, McDonald JC, Oksenberg JR, Bacchetti P and Waubant E: Vitamin D status is associated with relapse rate in pediatric-onset multiple sclerosis. Ann Neurol 67: 618-624, 2010.

38. Bhargava P, Steele SU, Waubant E, Revirajan NR, Marcus J, Dembele M, Cassard SD, Hollis BW, Crainiceanu C and Mowry EM: Multiple sclerosis patients have a diminished serologic response to vitamin D supplementation compared to healthy controls. Mult Scler 22: 753-760, 2016. 